\title{
Natural resistance of raw cotton fiber to heat evidenced by the suppressed depolymerization of cellulose
}

\author{
Sunghyun Nam, ${ }^{\mathrm{a},}$, Brian D. Condon ${ }^{\mathrm{a}}$, Yongliang Liu ${ }^{\mathrm{a}}$, Qingliang $\mathrm{He}^{\mathrm{b}}$
}

\begin{abstract}
Mechanically purified raw cotton fiber finds a growing range of applications in support of environmental sustainability, but its unique thermal stability, which is important in processes and utilization, is little known. This study shows that, at low temperatures $\left(<300{ }^{\circ} \mathrm{C}\right)$, the accelerated dehydration of cellulose was distinct in the pyrolysis of raw cotton. Compared with scoured cotton, raw cotton exhibited an intensive accumulation of dehydrocellulose in solid products, enhanced evolution of water and carbon dioxide, and increased formation of char. The amount of the crystalline region degraded together with the amorphous region was increased in raw cotton. The activation energy of thermal decomposition for raw cotton $(124 \mathrm{~kJ} / \mathrm{mol})$ determined under isothermal conditions at $200-300{ }^{\circ} \mathrm{C}$ was lower than that for scoured cotton $(202 \mathrm{~kJ} / \mathrm{mol})$. Such catalyzed low-temperature thermal reactions suppressed the depolymerization of cellulose at high temperatures, which produces highly volatile levoglucosan. The levoglucosan detected in raw cotton using Py-GC/MS was two orders of magnitude less abundant than that detected in scoured cotton.
\end{abstract}

Keywords: raw cotton; pyrolysis; inorganic salts; char; Py-GC/MS; TG-FTIR 


\section{Introduction}

Scouring and bleaching of cotton fiber conducted as pretreatments to remove waxes, proteins, pectin, and natural color consume large amounts of water, energy, and chemicals, causing high chemical oxygen demand and high biological oxygen demand in the textile effluents [1]. In particular, the environmental impact of hydrogen peroxide bleaching is intensive; the consumption of chemicals including a reducing agent (i.e., sodium thiosulfate), sodium hydroxide, and a wetting agent has been estimated to be 0.118 $\mathrm{kg} / \mathrm{kg}$ textile, and its energy and water consumption to be $8.34 \mathrm{MJ} / \mathrm{kg}$ textile and $50 \mathrm{~L} / \mathrm{kg}$ textile, respectively [2]. In an effort to minimize such negative impacts on the environment, the use of nonscoured, non-bleached raw cotton fiber is receiving growing attention [3]. After it is harvested and ginned, cotton fiber can be purified by re-ginning and lint-cleaning without using water or chemicals [4]. This mechanical cleaning was shown to greatly reduce microbial contamination, i.e., producing a 91\% drop in total aerobic microbial counts and a 99\% drop in total aerobic yeast/mold counts [5]. The natural oleophilic characteristics of raw cotton fiber enable efficient processing of nonwovens for a broad range of end-use applications, such as batting for furniture and mattresses, the acoustic insulation of automobiles, and disposable protective products; it also can serve as a sorbent for oil spill cleanup [6]. Moreover, the oleophilicity of the fiber can be controlled by the hydroentangling nonwoven processing for applications, where moisture absorbency is necessary [7].

In promoting the utilization of raw cotton, understanding its thermal properties, which influence aging, deterioration, and degradation at elevated temperatures, is important. A previous study [8] has shown that raw cotton fiber in either woven or nonwoven form has better thermal resistance than scoured cotton fiber. According to thermogravimetry, differential thermogravimetry, and microscale combustion calorimetry analyses, raw cotton exhibited much slower thermal decomposition with the lowered onset decomposition temperature, leaving five times greater char and $46 \%$ smaller heat release capacity, indicating its reduced flammability. This thermal stability of raw cotton was attributed to inorganics, most of which could be removed by the scouring process. The inorganic salts in the raw cotton, which are usually reported as ash (about 1.2\% of fiber dry weight), are expressed as the oxides of the elements [9]. In the ash constituent, 
potassium was the most abundant metal, and appreciable amounts of magnesium and calcium and smaller quantities of sodium and iron were included $\left(47.0 \% \mathrm{~K}_{2} \mathrm{O}, 10.0 \% \mathrm{MgO}, 7.6 \% \mathrm{SO}_{3}, 7.4 \% \mathrm{CaO}, 4.3 \% \mathrm{P}_{2} \mathrm{O}_{5}\right.$,

$570.5 \% \mathrm{Na}_{2} \mathrm{O}$, and $0.3 \% \mathrm{Fe}_{2} \mathrm{O}_{3}$ ) [10]. These inorganic salts were found to catalyze the dehydration of 58 cellulose at low temperatures to improve the formation of carbonaceous char [8].

59 Although the previous research has revealed the distinct thermal and combustion properties of raw 60 cotton, the findings do not provide a comprehensive understanding of the altered thermal pathways

61 involved. The suppression of the depolymerization route was suggested but has not yet been proved for

62 raw cotton. Moreover, the activation energy of the thermal decomposition for raw cotton as determined

63 from the region where the major weight loss occurred $\left(>300{ }^{\circ} \mathrm{C}\right)$ did not fully elucidate the catalyzed

64 thermal reactions at low temperatures. The objective of this study is to verify the changes in the nature of 65 the pyrolytic reactions of cotton in the presence of naturally occurring inorganic salts. The isothermal 66 thermogravimetric analysis at $200-320^{\circ} \mathrm{C}$ was conducted to determine the kinetic parameters, including 67 activation energy. The progress and products of low-temperature reactions greatly affected subsequent, 68 competitive reactions at high temperatures. Such modification was demonstrated by monitoring the 69 chemical and structural changes in the solid substrate as well as gaseous products released in the entire 70 range of the pyrolysis temperature, using FTIR-ATR and TG-FTIR, respectively. The quantitative 71 analysis of the composition of gas evolved by pyrolysis-gas chromatography/mass spectrometry 72 confirmed the substantial reduction in "unzipping" depolymerization reaction in raw cotton. By 73 combining the results of these kinetic and analytical studies, it was possible to develop a more complete 74 picture of the pyrolytic reactions that characterize raw cotton and the resulting resistance to heat.

75

\section{Experimental}

77 Raw cotton plain woven fabric (greige cotton duck, $237 \mathrm{~g} / \mathrm{m} 2$ ) was purchased from Testfabrics, Inc.

78 Alkaline scouring was carried out using an overflow-jet dyeing apparatus (Werner Mathis Inc.). Fabric

79 was immersed in an aqueous solution containing $\mathrm{NaOH}(1.8 \mathrm{~g} / \mathrm{L})$ and Triton $\mathrm{X}-100(0.2 \mathrm{~g} / \mathrm{L})$ with a 
liquid-to-fabric ratio of $22: 1$ and circulated at $100{ }^{\circ} \mathrm{C}$ for $60 \mathrm{~min}$. After treatment, the fabric was washed in circulating water at $100{ }^{\circ} \mathrm{C}$ for $20 \mathrm{~min}$, followed by cold-water washing for $20 \mathrm{~min}$. The scoured fabric was neutralized with a solution of acetic acid $(0.25 \mathrm{~g} / \mathrm{L})$ in water for $10 \mathrm{~min}$ and then rinsed with cold water. The fabric was then passed through a continuous hot-air dryer (Werner Mathis Inc.).

Thermogravimetric (TG) analysis was carried out using a TGA Q500 thermal gravimetric analyzer (TA Instruments, New Castle, DE) under a nitrogen atmosphere. The nitrogen flow into the furnace was maintained at a rate of $90 \mathrm{~mL} / \mathrm{min}$. About $6 \mathrm{mg}$ of the sample placed in a platinum pan was heated from $30 \pm 5{ }^{\circ} \mathrm{C}$ to various temperatures $\left(200-900{ }^{\circ} \mathrm{C}\right)$ with a heating rate of $10{ }^{\circ} \mathrm{C} / \mathrm{min}$ and was then immediately removed from the furnace. The images of the heated samples were taken using a digital microscope (KH-8700, Hirox) with a magnification of $10 \mathrm{X}$ in reflection mode. The isothermal experiments at low temperatures were conducted with 5 heating steps. The temperature was increased to $105{ }^{\circ} \mathrm{C}$ with a heating rate of $20^{\circ} \mathrm{C} / \mathrm{min}$ and held for $10 \mathrm{~min}$ to remove the moisture from the sample. The temperature was then increased to the specified isothermal temperature $\left(200-320^{\circ} \mathrm{C}\right)$ at a heating rate of $20{ }^{\circ} \mathrm{C} / \mathrm{min}$ and maintained for $1 \mathrm{~h}$. Afterward, the sample was pyrolyzed at a heating rate of $10{ }^{\circ} \mathrm{C} / \mathrm{min}$ until $900{ }^{\circ} \mathrm{C}$ was attained. TG and DTG thermograms were analyzed using Universal Analysis 2000 software (TA Instruments). Three measurements were performed.

The evolved gas during the thermal decomposition of cotton was analyzed using TG-FTIR. A TG analyzer was equipped with a gas purge, and a TG-FTIR interface was installed inside the infrared spectrometer. Nitrogen was purged at $90 \mathrm{ml} / \mathrm{min}$. The temperature was increased from $100{ }^{\circ} \mathrm{C}$ to $550{ }^{\circ} \mathrm{C}$ at a heating rate of $10{ }^{\circ} \mathrm{C} / \mathrm{min}$. A series of FTIR spectra were collected with 16 scans at a $4 \mathrm{~cm}^{-1}$ resolution. Two spectra were obtained every minute.

The FTIR spectra of the samples heated at various temperatures were collected using an FTS 3000MX FTIR spectrometer (Varian Instruments, Randolph, MA) equipped with a ceramic source, $\mathrm{KBr}$ beam splitter, and deuterated triglycine sulfate detector. The attenuated total reflection (ATR) sampling device utilized a DuraSamplIR single-pass diamond-coated internal reflection accessory (Smiths 
Detection, Danbury, CT), and consistent contact pressure was applied by a stainless steel rod and an electronic load display. Three measurements at different locations for each sample were collected over the range of $4000-600 \mathrm{~cm}^{-1}$ at $4 \mathrm{~cm}^{-1}$ resolution and 16 scans. All spectra were given in absorbance and no ATR correction was applied. Following the import to the GRAMS IQ application in Grams/AI (Version 9.1, Thermo Fisher Scientific, Waltham, MA), the spectra were smoothed with a Savitzky-Golay function $($ polynomial $=2$ and points $=11)$.

Pyrolysis-gas chromatography/mass spectrometry (Py-GC/MS) analysis was carried out at the

112 Complex Carbohydrate Research Center in Athens, GA. 400-600 $\mu \mathrm{g}$ of sample was weighed and heated 113 in the pyrolyzer at a range of temperatures. The released vapors were analyzed using GC/MS (Agilent 114 technologies, CA). The temperature of the GC-MS interface was held at $280{ }^{\circ} \mathrm{C}$. Helium was used as a carrier gas at a constant flow rate of $1 \mathrm{~mL} / \mathrm{min}$ and a 50:1 split ratio. The column temperature was increased from $50{ }^{\circ} \mathrm{C}$ to $280{ }^{\circ} \mathrm{C}$ at the heating rate of $5{ }^{\circ} \mathrm{C} / \mathrm{min}$ and maintained at $280{ }^{\circ} \mathrm{C}$ for $5 \mathrm{~min}$. 117 Assignments of chromatographic peaks were made from mass spectral detection (NIST MS library).

\section{Results and discussion}

Raw and scoured cotton fabrics heated at incremental temperatures $\left(200-400{ }^{\circ} \mathrm{C}\right)$ under a nitrogen atmosphere were examined. Figure 1 shows that, as the temperature increased, the raw cotton was

122 discolored faster than the scoured cotton; a brown (and black) color appeared in raw cotton at about $40{ }^{\circ} \mathrm{C}$ 123 lower temperature. Agreeing with the color change, the raw cotton exhibited greater weight loss in the 124 early decomposition, and this weight-loss difference increased until the temperature reached $340{ }^{\circ} \mathrm{C}$. 125 Above $340{ }^{\circ} \mathrm{C}$, the weight-loss rates for raw and scoured cottons increased to reach the maximum weight126 loss rate temperatures $\left(T_{\max }\right), 350.1$ and $356.7^{\circ} \mathrm{C}$, respectivly. When the main decomposition of cellulose 127 ended (at around $370{ }^{\circ} \mathrm{C}$ for raw cotton and $380{ }^{\circ} \mathrm{C}$ for scoured cotton), the raw cotton was consumed to a 128 much lesser extent than the scoured cotton (75\% vs. 94\%). The larger amount of char produced in raw 129 cotton was maintained until the temperature reached $900{ }^{\circ} \mathrm{C}$. Such accelerated decomposition of raw 
131 gaseous products.

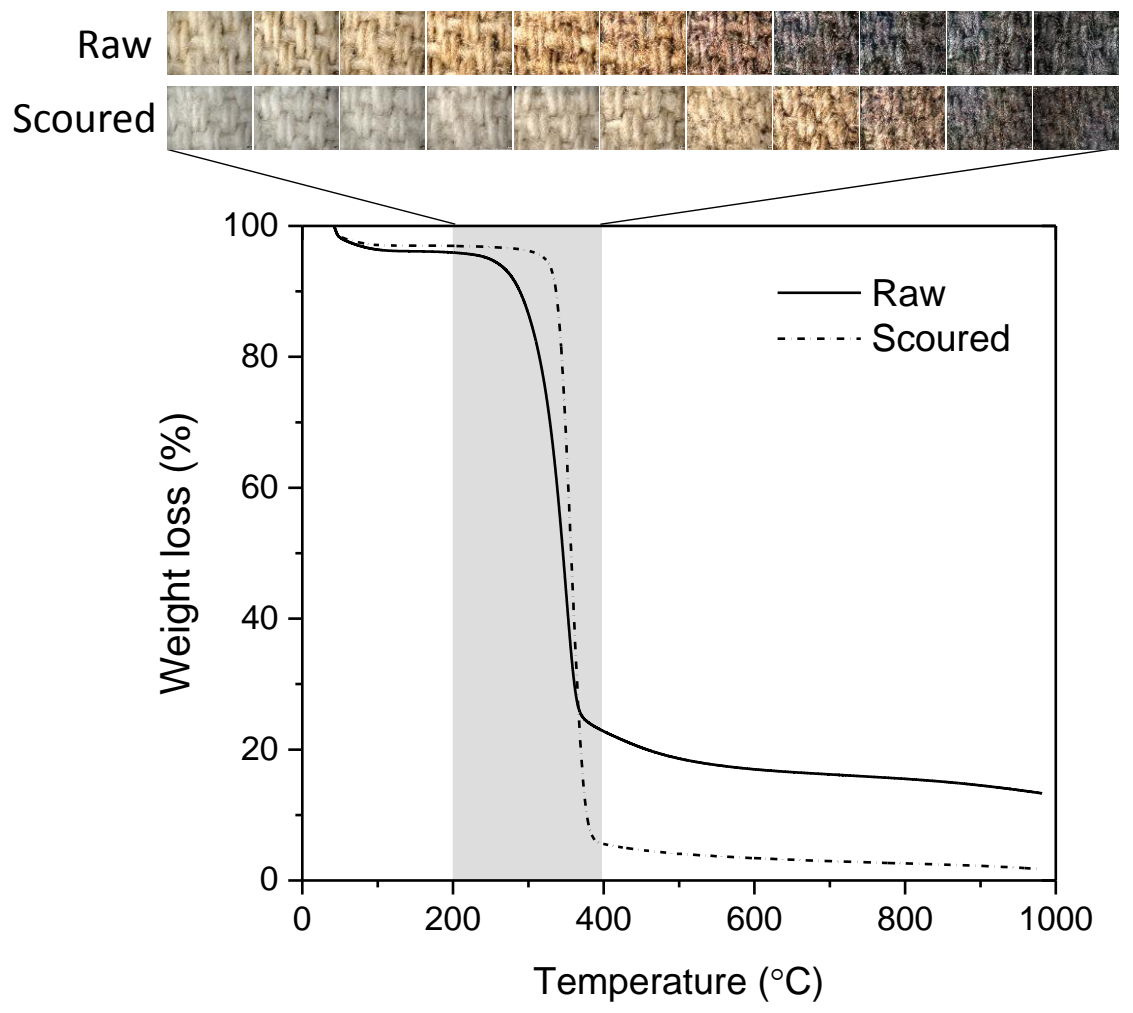

134 Figure 1. The optical microscopic images (10X) of raw and scoured cotton fabrics heated from $200{ }^{\circ} \mathrm{C}$ to $400{ }^{\circ} \mathrm{C}$ at increments of $20^{\circ} \mathrm{C}$ in the $\mathrm{TG}$ analyzer under a nitrogen atmosphere.

\subsection{Isothermal kinetics between 200 and $300^{\circ} \mathrm{C}$}

Figures 2 (a) and (b) show the TG curves and three-dimensional profiles of conversion for raw and scoured cotton fabrics, respectively. After the first weight-loss period corresponding to the removal of moisture, raw and scoured cotton fabrics showed distinct weight-loss behaviors at various isothermal temperatures $\left(200-320{ }^{\circ} \mathrm{C}\right)$. Raw cotton started to show a noticeable weight decrement $(>5 \%)$ at $240{ }^{\circ} \mathrm{C}$,

142 whereas scoured cotton prolonged the corresponding decremental temperature to $280{ }^{\circ} \mathrm{C}$. Until the

143 temperature reached $300{ }^{\circ} \mathrm{C}$, the weight loss of raw cotton was greater, but at $320^{\circ} \mathrm{C}$, the weight loss of 144 scoured cotton abruptly increased to exceed the weight loss of raw cotton. Figure 3 (a) shows that the 
145 isothermal process under temperatures up to $260{ }^{\circ} \mathrm{C}$ did not influence the $T_{\max }$ values for raw and scoured 146 cottons; however, the preheating at $280{ }^{\circ} \mathrm{C}$ and $300{ }^{\circ} \mathrm{C}$ influenced the thermal decomposition of cellulose, 147 decreasing the $T_{\max }$. Under $320^{\circ} \mathrm{C}$, where most cellulose had degraded, $T_{\max }$ could not be observed. Figure 1483 (b) shows that the isothermal treatments at low temperatures tended to increase the char yield. A similar 149 effect was also observed in other studies [11,12] and explained as the rearrangement of the cellulose 150 structure through the dehydration and cross-linking reactions, which promotes the final production of char 151 residue $[13,14]$.

(a)
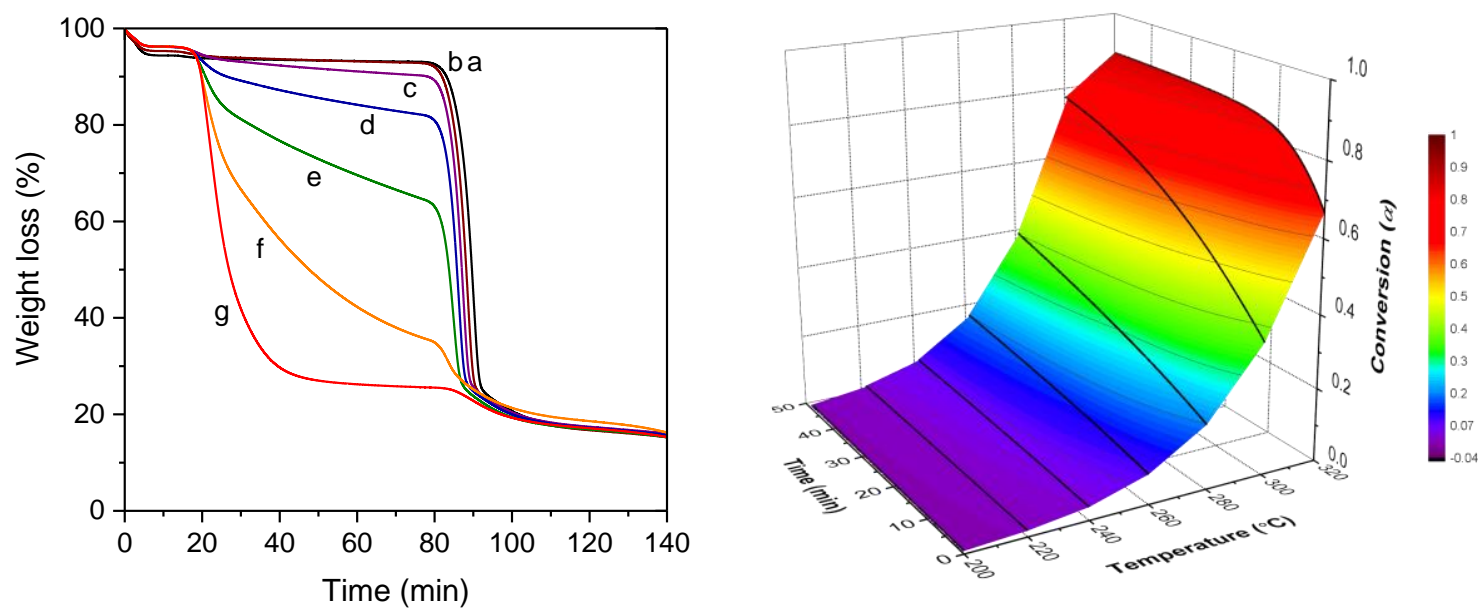

(b)
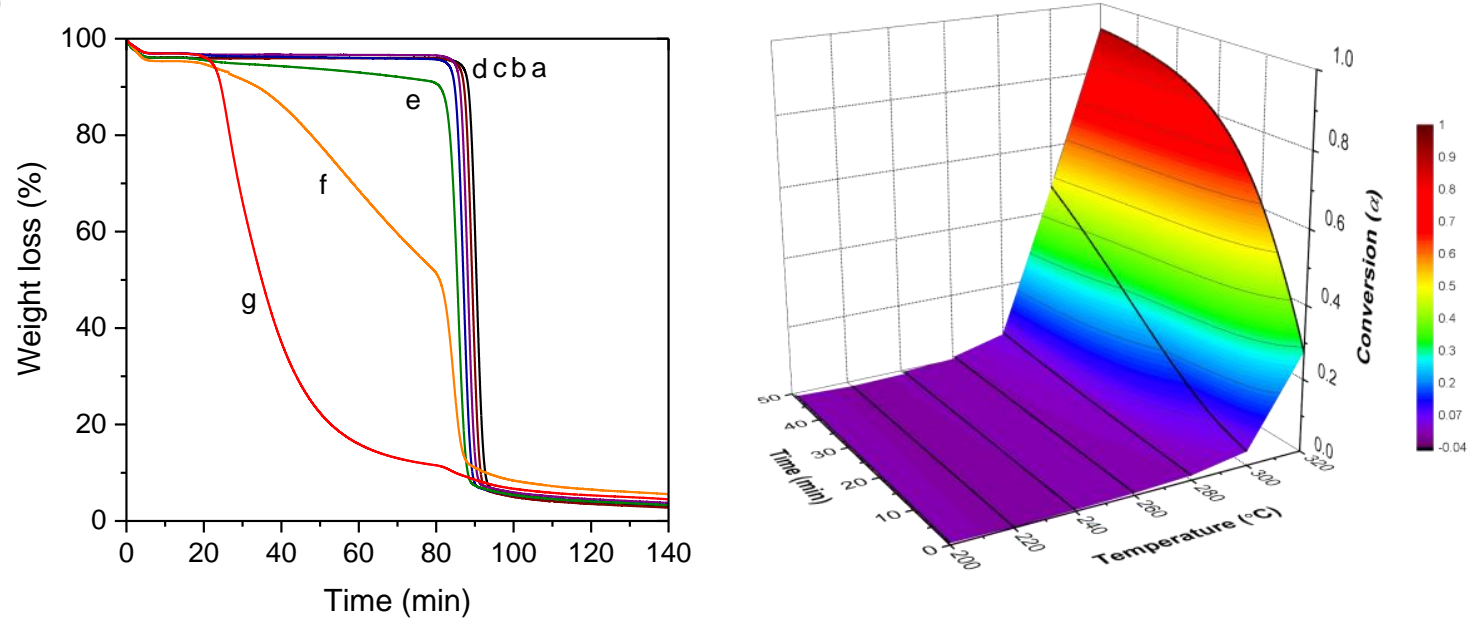

Figure 2. Isothermal TG thermograms (left) for (a) raw and (b) scoured cotton fabrics at $200-320{ }^{\circ} \mathrm{C}(\mathrm{a}-\mathrm{g}$ 154 at increments of $20^{\circ} \mathrm{C}$ ) and the corresponding three-dimensional profiles of conversion (right). 
(a)

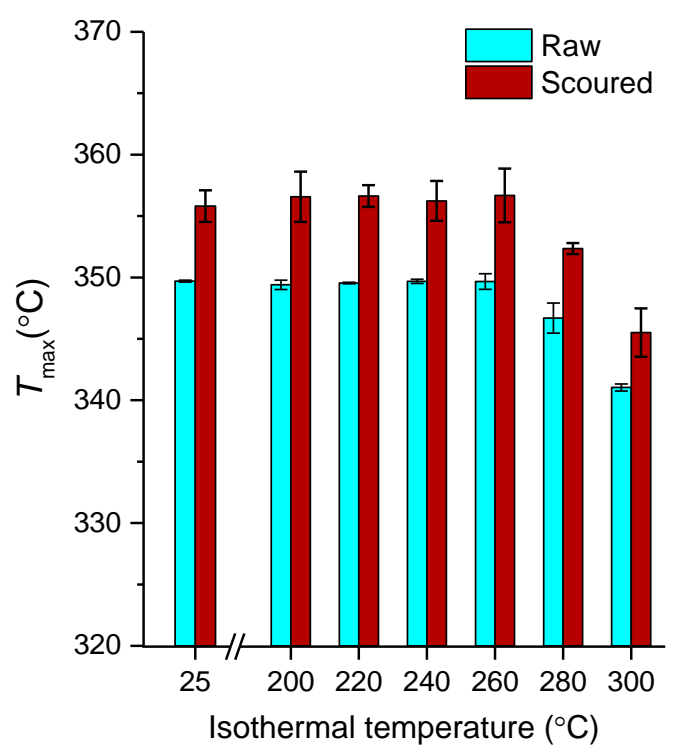

(b)

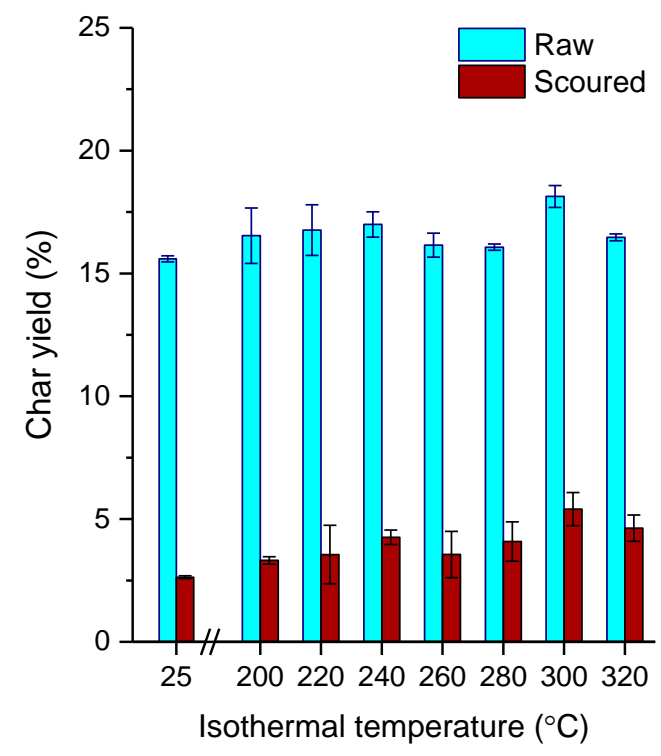

155

156

157

158

159

160

161

$\frac{d \alpha}{d t}=k(1-\alpha)$

162

163

164

$$
\alpha=\frac{w_{0}-w_{t}}{w_{0}-w_{f}}
$$

where $w_{0}, w_{\mathrm{t}}$, and $w_{\mathrm{f}}$ are the initial sample weight, the sample weight at time $t$, and the final sample weight, respectively. In this study, the sample weight at $105^{\circ} \mathrm{C}$ after 5 min was used for $w_{0}$, and the weight at 800

$167{ }^{\circ} \mathrm{C}$ was used for $w_{\mathrm{f}}$. The integration of Eq. (1) gives:

$168 \ln \left(\frac{1-\alpha_{0}}{1-\alpha}\right)=k\left(t-t_{0}\right)$ 
169 where $\alpha_{0}$ is the conversion of the sample from the beginning of the isothermal process at $t=t_{0}$. The plot 170 of $\ln \left(1-\alpha_{0}\right)$ versus $\left(t-t_{0}\right)$ yields a straight line with the slope equal to the rate constant $k$. For the 171 determination of a rate constant, the isothermal period for the scoured cotton was additionally extended

172 until it reached the same level of weight loss as in raw cotton. The dependence of $k$ on temperature is

173 assumed to obey the Arrhenius equation:

$174 k=A \exp \left(\frac{-E_{a}}{R T}\right)$

175 where $A$ is the pre-exponential factor $\left(\min ^{-1}\right), E_{\mathrm{a}}$ is the activation energy $(\mathrm{kJ} / \mathrm{mol})$, and $R$ is the gas 176 constant $(8.314 \mathrm{~J} / \mathrm{K} \cdot \mathrm{mol})$. From the logarithmic form of Ep. (4), the plot $\ln (k)$ versus $T^{1}$ yields a straight 177 line with a slope of $-E_{\mathrm{a}} / R$ and an intercept of $\ln (A)$. As shown in Table 1 , all of the coefficients of 178 determination were greater than 0.99 , indicating adherence to the first-order reaction model. The rate 179 constants $(k)$ for raw cotton were one order of magnitude greater than those for scoured cotton. Figure 4 180 shows the plots of $\ln (k)$ as a function of $T^{1}$, yielding straight lines. The steeper slope observed for scoured 181 cotton indicates its higher activation energies $\left(E_{\mathrm{a}}\right)$ for the isothermal decomposition. The $E_{\mathrm{a}}$ values for 182 raw and scoured cottons were determined to be 123.9 and $201.8 \mathrm{~kJ} / \mathrm{mol}$, respectively.

183

184 Table 1. Kinetic parameters obtained by least square fitting of the isothermal data for raw and scoured 185 cotton fabrics based on the first-order reaction model.

\begin{tabular}{ccccccc}
\hline Sample & Temperature $\left({ }^{\circ} \mathrm{C}\right)$ & $n^{\mathrm{a}}$ & $k^{\mathrm{b}}\left(\mathrm{min}^{-1}\right)$ & $R^{2}$ & $E_{a}^{\mathrm{c}}(\mathrm{kJ} / \mathrm{mol})$ & $A^{\mathrm{d}}\left(\mathrm{min}^{-1}\right)$ \\
\hline & 200 & 1 & $7.28 \times 10^{-5}$ & 0.9982 & & \\
Raw & 220 & 1 & $3.04 \times 10^{-4}$ & 0.9970 & & \\
cotton & 240 & 1 & $8.22 \times 10^{-4}$ & 0.9944 & & \\
& 260 & 1 & $2.20 \times 10^{-3}$ & 0.9946 & 123.9 & $3.56 \times 10^{9}$ \\
& 280 & 1 & $6.25 \times 10^{-3}$ & 0.9984 & & \\
& 300 & 1 & $2.15 \times 10^{-2}$ & 0.9966 & & \\
Scoured & 200 & 1 & $1.95 \times 10^{-6}$ & 0.9952 & & \\
cotton & 220 & 1 & $8.56 \times 10^{-6}$ & 0.9978 & & \\
& 240 & 1 & $4.78 \times 10^{-5}$ & 0.9962 & 201.8 & $2.59 \times 10^{16}$ \\
& 260 & 1 & $3.77 \times 10^{-4}$ & 0.9922 & &
\end{tabular}




$\begin{array}{llll}280 & 1 & 2.24 \times 10^{-3} & 0.9992 \\ 300 & 1 & 1.42 \times 10^{-2} & 0.9998\end{array}$

a order of reaction; ${ }^{b}$ rate constant; ${ }^{\mathrm{c}}$ activation energy; ${ }^{\mathrm{d}}$ pre-exponential factor

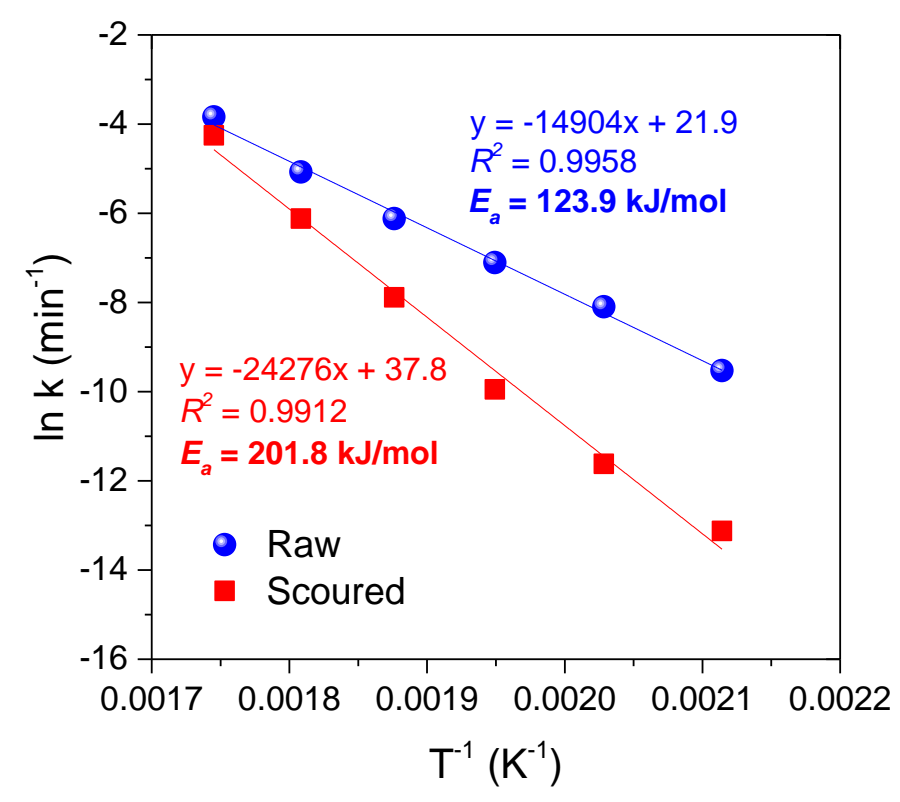

187

Figure 4. Plots of $\ln (k)$ versus $T^{1}$ for the determination of the activation energies and pre-exponential factors in the isothermal decomposition from $200{ }^{\circ} \mathrm{C}$ to $300{ }^{\circ} \mathrm{C}$ for raw and scoured cotton fabrics.

\subsection{Analysis of solid products}

Figures 5 (a) and (b) show the FTIR-ATR spectra of raw and scoured cotton fabrics, respectively, heated from $180{ }^{\circ} \mathrm{C}$ to $880{ }^{\circ} \mathrm{C}$. The published band assignments on the cellulose structure [15-18] are 194 given in parentheses. The cellulose characteristic bands, $\mathrm{C}-\mathrm{H}$ stretching $\left(3000-2700 \mathrm{~cm}^{-1}\right)$ and $\mathrm{C}-\mathrm{H}$ 195 wagging $\left(1429 \mathrm{~cm}^{-1}\right)$ bands, started to broaden at $220{ }^{\circ} \mathrm{C}$ in raw cotton, whereas these bands remained stable at temperatures up to $280{ }^{\circ} \mathrm{C}$ in scoured cotton. Another noticeable difference was the development

197 of the bands at $1695 \mathrm{~cm}^{-1}$ and $1600 \mathrm{~cm}^{-1}$, corresponding to $\mathrm{C}=\mathrm{O}$ stretching of unsaturated aldehydes and $198 \mathrm{C}=\mathrm{C}$ stretching of alkenes, respectively, which indicate the dehydration of cellulose. These bands were 199 intensified at $300-380{ }^{\circ} \mathrm{C}$ for raw cotton and at $360-480{ }^{\circ} \mathrm{C}$ for scoured cotton. The facilitated dehydration 200 at lower temperatures in raw cotton was also supported by the early disappearance of C-O-C stretching 
$201\left(1160 \mathrm{~cm}^{-1}\right)$ and $\mathrm{C}-\mathrm{O}$ stretching $\left(1029 \mathrm{~cm}^{-1}\right)$ bands at $360{ }^{\circ} \mathrm{C}\left(480{ }^{\circ} \mathrm{C}\right.$ for scoured cotton $)$. The shift of the $202 \mathrm{C}=\mathrm{C}$ stretching band toward $1575 \mathrm{~cm}^{-1}$, signifying conjugation of $\mathrm{C}=\mathrm{C}$ bonds, occurred in raw cotton at $203360{ }^{\circ} \mathrm{C}$, but no such shift was observed until the temperature reached $580{ }^{\circ} \mathrm{C}$ in scoured cotton. According 204 to Price et al. [19], the conversion of aliphatic char from cellulose to an aromatic form occurred at 400$800{ }^{\circ} \mathrm{C}$ in air. These results suggest that traces of inorganic salts in raw cotton allowed the aromatization of char at lower temperatures, which contributed to the increased formation of stable char. The early 207 formation of aromatic char was also observed by flame-retardant treatments, i.e., the introduction of 208 flame-retardant phosphoric acid into cellulose lowered the temperature for the accumulation of 209 unsaturated carbon-carbon bonds and carbonyl groups in solid pyrolysis products [20], and inorganic 210 phosphorus/nitrogen flame retardants led to direct formation of an aromatic char [19].

211 The change in the crystallinity of cellulose was examined using a previously developed three-band $212\left(800,730\right.$, and $\left.708 \mathrm{~cm}^{-1}\right)$ ratio algorithm [21, 22]. Figure 6 (a) shows the variations in the crystallinity 213 index $(\mathrm{CI})$ for raw and scoured cottons under conditions of increasing temperature. The scouring process 214 slightly increased the CI. As the temperature increased, the CI values of both raw and scoured cottons 215 noticeably increased. As shown in Figure $6(\mathrm{~b})$, the change in the intensity at $730 \mathrm{~cm}^{-1}$, which is linked 216 with the relative amount of amorphous cellulose, suggests that the observed elevations in CI were 217 attributed to the decomposition of the amorphous region. This is supported by Basch and Lewin [23], who 218 reported that thermal decomposition of the cellulose begins in the less-ordered regions by demonstrating a 219 drop in the degree of polymerization and increased crystallinity for various cellulose materials during 220 vacuum pyrolysis at $251^{\circ} \mathrm{C}$. They also reported that the rate of decomposition increased as the percentage 221 of amorphous region increased. Raw cotton exhibited a significant correlation between the percentage of 222 the amorphous region $(100-\mathrm{CI})$ and the weight-loss rate (obtained by DTG) with a coefficient of 0.79 ( $p$ $223<0.01)$, but scoured cotton exhibited no significant correlation due to the absence of appreciable weight 224 loss until the temperature reached $320{ }^{\circ} \mathrm{C}$. It is noted that the amorphous intensity at $730 \mathrm{~cm}^{-1}$ decreased 225 faster for raw cotton than for scoured cotton. Trace quantities of inorganic salts present in raw cotton 
227 that, before its amorphous region completely degraded, the crystalline region started to degrade, yielding

$22880 \%$ of the maximum CI at around $240{ }^{\circ} \mathrm{C}$. On the other hand, the decomposition of the amorphous

229 cellulose in scoured cotton was prolonged at temperatures up to $330^{\circ} \mathrm{C}$, at which complete decomposition

230 of the amorphous region was achieved. It should be noted that, as this algorithm was developed based on

231 the maturity of cotton fiber, the CI values determined for heated cottons might be overestimated. The

232 relative changes in $\mathrm{CI}$, however, clearly indicate that a greater amount of the crystalline region degraded

233 together with the amorphous region in raw cotton than in scoured cotton. It has been reported that the

234 facilitated thermal decomposition of amorphous as well as crystalline regions, which was observed

235 following the addition of phosphoric acid, was associated with dehydration reactions and other types of

236 rearrangements of cellulose [25]. After reaching the maximum CI, the CI for the scoured cotton dropped

237 steeply to $0 \%$. The temperature for $0 \% \mathrm{CI}$ was $360{ }^{\circ} \mathrm{C}$ for raw cotton and $480{ }^{\circ} \mathrm{C}$ for scoured cotton.
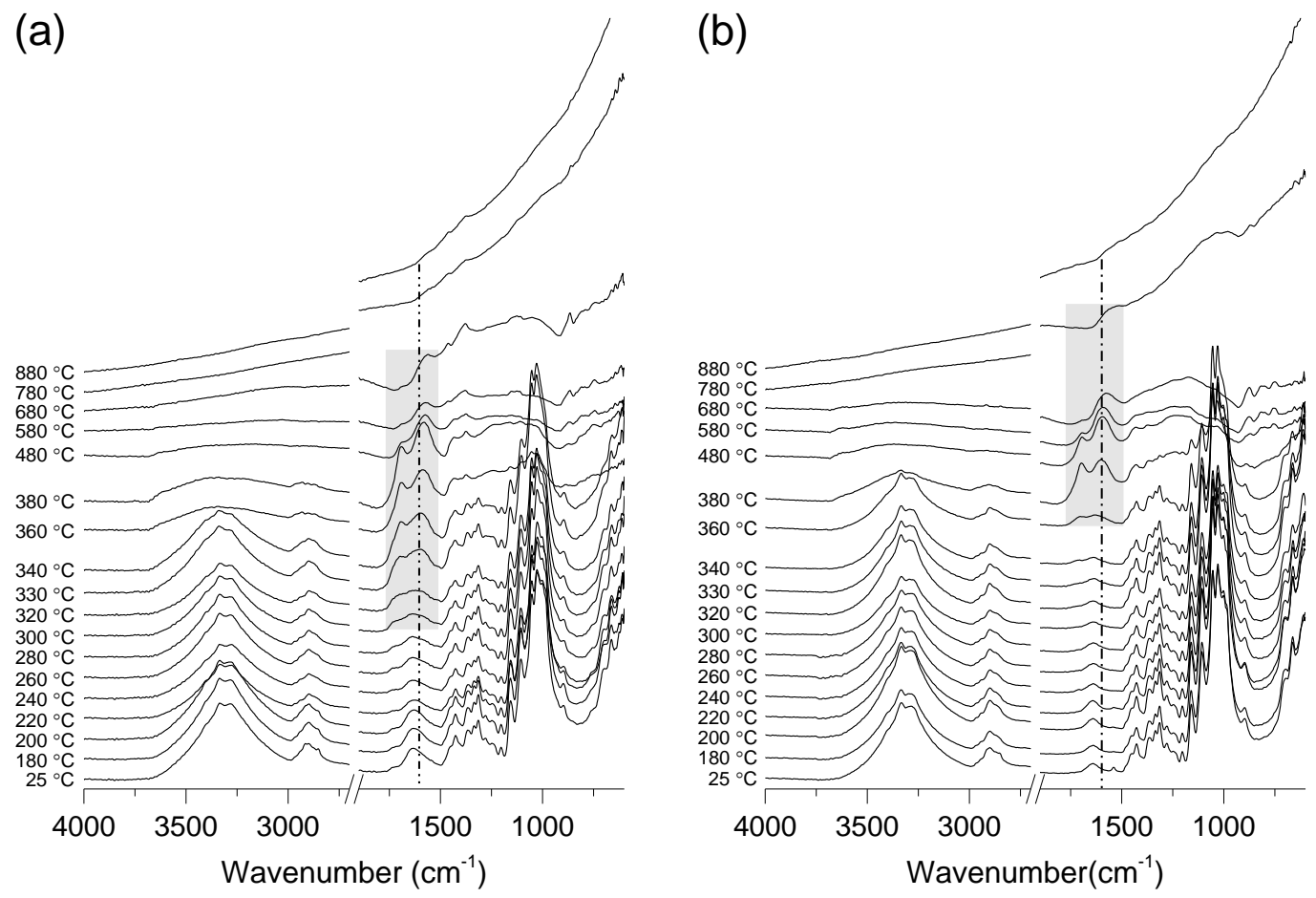

Figure 5. FTIR-ATR spectra for (a) raw cotton and (b) scoured cotton heated at incremental temperatures. 

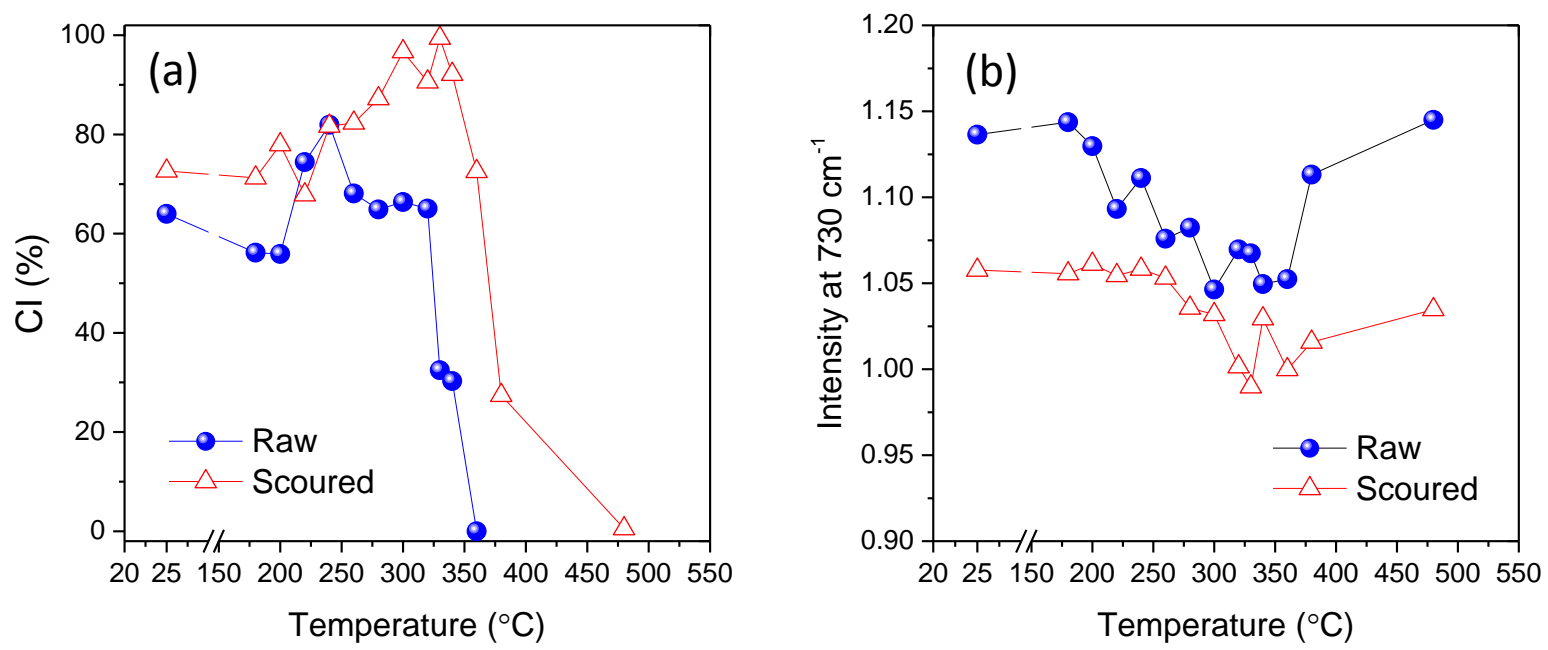

241

Figure 6. (a) crystallinity index calculated by the three-band ratio algorithm and (b) intensities at $740 \mathrm{~cm}^{-}$

${ }^{1}$ for raw and scoured cotton fabrics heated at incremental temperatures.

\subsection{Analysis of gaseous products}

The real-time gaseous products that evolved during the pyrolysis process were detected by TG analysis coupled with IR spectroscopy. Figure 7 shows the 3D FTIR spectra with the coordinates of absorbance, wavenumber, and temperature for raw and scoured cottons. The evolved species consisted primarily of water $\left(3737,3590,1514 \mathrm{~cm}^{-1}\right)$, methane $\left(2977,2918,2819,2725 \mathrm{~cm}^{-1}\right)$, carbon dioxide

251 alcohols $\left(1117,1060 \mathrm{~cm}^{-1}\right)$. In accordance with the weight-loss pattern seen in the TG curve (Figure 1), two stages of evolution were observed. The first noticeable simultaneous evolution of gases was detected near $210{ }^{\circ} \mathrm{C}$ for raw cotton and $300{ }^{\circ} \mathrm{C}$ for scoured cotton; their absorbance gradually increased as the temperature increased, reaching apexes at around $325{ }^{\circ} \mathrm{C}$ and $340{ }^{\circ} \mathrm{C}$ (close to their $T_{\max }$ values), respectively. The greater evolution concentrations (i.e., higher absorbance) and wider evolution temperature intervals of water, carbon dioxide, carbon monoxide, and aldehydes for raw cotton show its

257 progressive dehydration of the cellulose in the range of $210-280^{\circ} \mathrm{C}$, followed by the decomposition of the 258 dehydrocellulose into gaseous products and char above $280^{\circ} \mathrm{C}$. The dehydrocellulose could be formed via 
etherification between superimposed cellulose chains (C-2 and C-4) [26]. The near absence of peaks

260 detected for carbon monoxide in scoured cotton, which is one of the decomposition products of ether

261 groups, was consistent with its suppressed dehydration. The production of methane requiring relatively

262 high energy in breaking methyl and methylene groups [27] was favored in the high-temperature

263 decomposition of scoured cotton. The second evolution stage was clearly identified in raw cotton from its

264 carbon dioxide absorbance wave, which intensified again at around $390{ }^{\circ} \mathrm{C}$. This growing absorbance

265 (reaching the maximum at $467{ }^{\circ} \mathrm{C}$ and stabilizing afterwards) indicates the decomposition of char formed

266 in the previous stage. The negligible char formation in scoured cotton (Figure 1) resulted in the emission

267 of a lower concentration of carbon dioxide. Carbon monoxide, methane, and aldehydes were rarely

268 detected in the second stage. The absorbance band centered at $3260 \mathrm{~cm}^{-1}(\mathrm{O}-\mathrm{H}$ stretching) continuously

269 increased throughout the pyrolysis process.
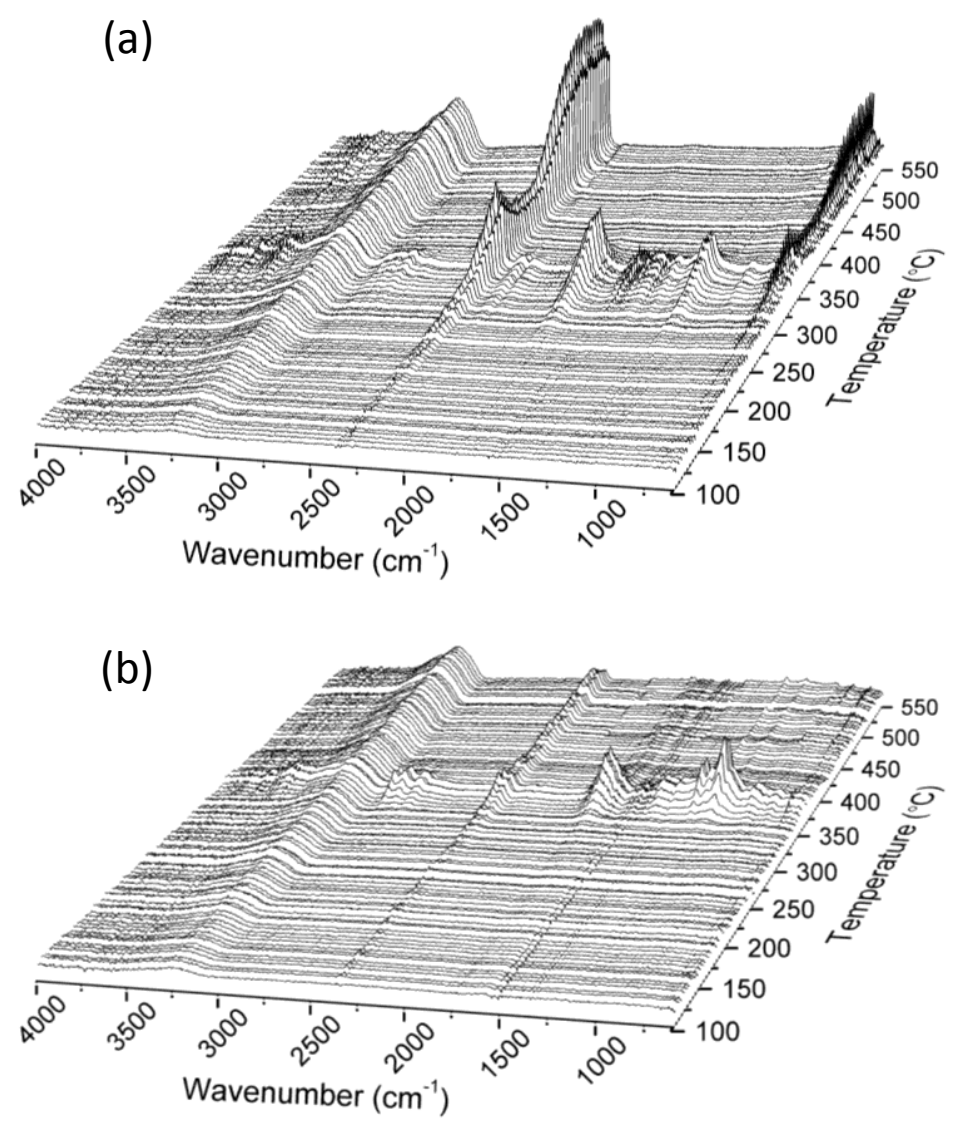

271 Figure 7. 3D TG-FTIR spectra for (a) raw cotton and (b) scoured cotton obtained at a heating rate of 10 $272{ }^{\circ} \mathrm{C} / \mathrm{min}$. 
Py-GC/MS chromatograms for raw and scoured cottons obtained at $320{ }^{\circ} \mathrm{C}$ and $530{ }^{\circ} \mathrm{C}$ are presented

274 in Figures 8 (a) - (d). Prospective assignments of the main peaks made from mass spectral detection 275 (NIST MS library) are presented in Tables 2 and 3. At $320^{\circ} \mathrm{C}$, raw cotton released a large variety of 276 products, whereas scoured cotton produced levoglucosan ( $\beta$-D-glucopyranose, 1,6-anhydro) as a major 277 decomposition product. Levoglucosan is generally formed from the depolymerization of cellulose, which 278 involves the intramolecular transglycosidation breaking the 1,4-glycosidic linkage. The resulting 279 anhydrosugars were then converted into the more stable levoglucosan [28]; its furanose isomer (i.e., 1,6280 anhydro- $\beta$-D-glucofuranose) was detected in scoured cotton. A high production rate of levoglucosan, as 281 seen in scoured cotton, characterized the depolymerization as an "unzipping" process.

282 Raw cotton's low yield of levoglucosan and production of a variety of five and six carbon compounds 283 suggest the accelerated dehydration of the glucose units and anhydrosugars. The dehydration products 284 detected include hydroxyacetone, furan derivatives, levoglucosenone, and pyran derivatives, which are 285 important intermediates in char formation [29, 30]. Similarly, the rapid decrease in crystallinity of raw 286 cotton (Figure 6) resulted in reducing its levoglucosan production [23]. It is noted that the peak area of 287 levoglucosenone was greater than that of levoglucosan. The increased ratio of levoglucosenone to 288 levoglucosan has been reported to be characteristic of the pyrolysis of cellulose modified with flame289 retardant phosphoric acid [25, 31]. The greater abundance of levoglucosan for scoured cotton was 290 maintained as the temperature increased to $530{ }^{\circ} \mathrm{C}$. The maximum production of levoglucosan during the 291 pyrolysis of cellulose was reported as occurring at around $570{ }^{\circ} \mathrm{C}$ [32]. At $530{ }^{\circ} \mathrm{C}$, various low-molecular292 weight volatiles were produced from the secondary cracking of the primary fragments. The generation of 293 a variety of cyclopentene derivatives as well as phenol and phenol derivatives was promoted in raw cotton. 294 The presence of 1,4:3,6-dianhydro- $\alpha$-d-glucopyranose, furan derivatives, and pyran derivatives detected 295 in scoured cotton show that the dehydration of levoglucosan occurred at $530{ }^{\circ} \mathrm{C}$. 
(a) Raw cotton at $320^{\circ} \mathrm{C}$

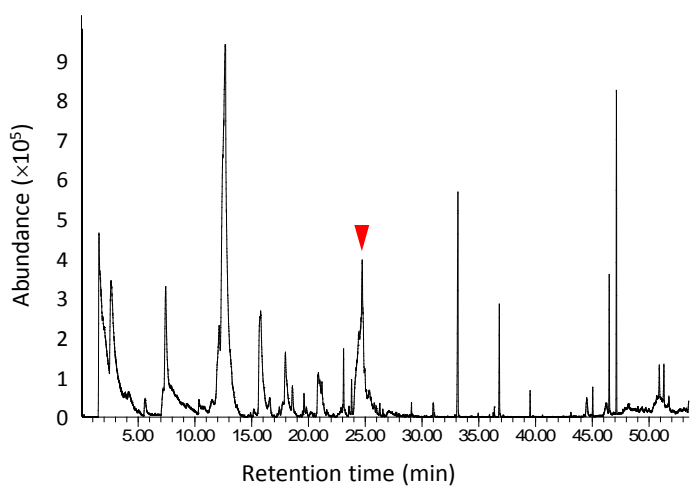

(c) Raw cotton at $530{ }^{\circ} \mathrm{C}$

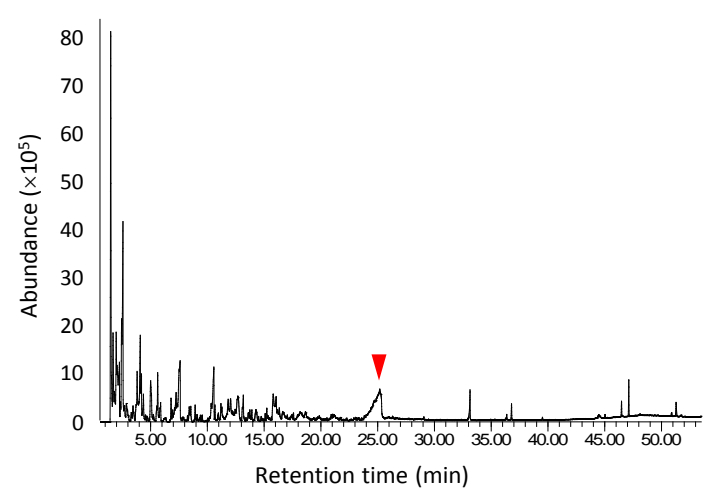

Retention time: 24.913 - $31.099 \mathrm{~min}$

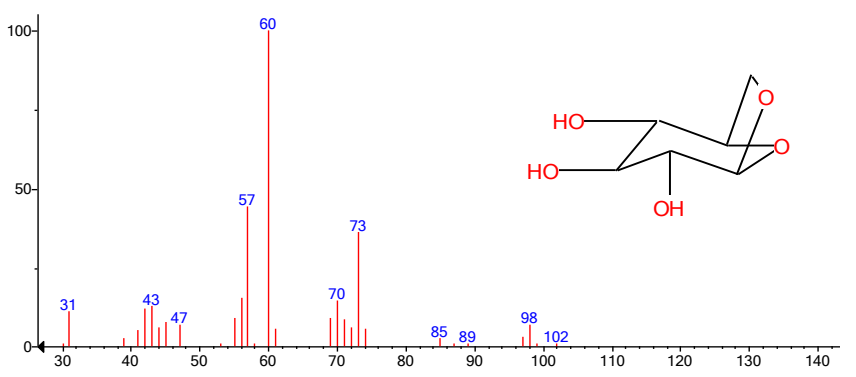

Figure 8. Py-GC/MS chromatograms for (a, c) raw and (b, d) scoured cottons at $320{ }^{\circ} \mathrm{C}$ and $530{ }^{\circ} \mathrm{C}$. (e)

301 levoglucosan as a function of temperature. (b) Scoured cotton at $320^{\circ} \mathrm{C}$

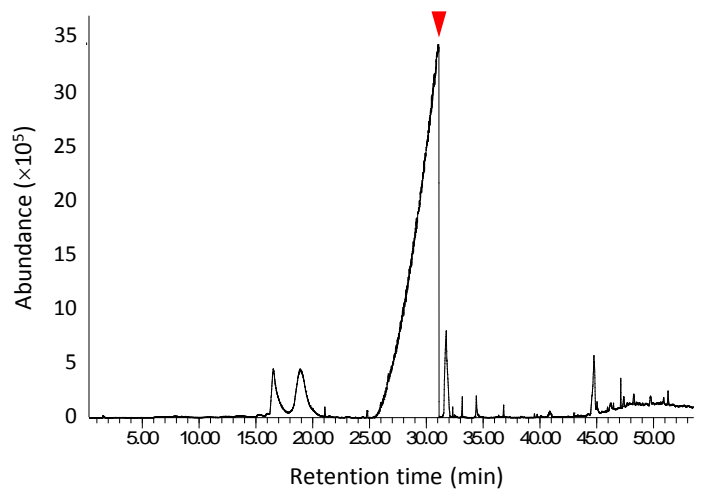

(d) Scoured cotton at $530^{\circ} \mathrm{C}$
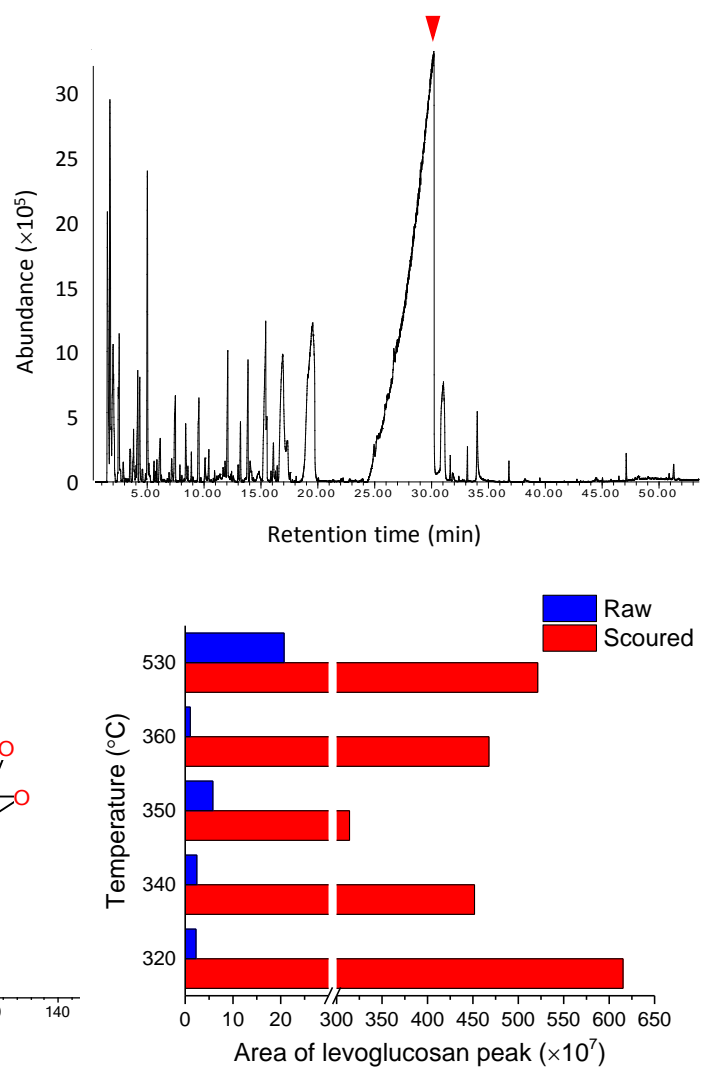

302 
Table 2. Selected compounds identified from the Py-GC/MS analysis for raw and scoured cotton fabrics 305 at $320{ }^{\circ} \mathrm{C}$.

\begin{tabular}{clll}
\hline \multicolumn{1}{c}{ Raw cotton } & \multicolumn{1}{c}{ Scoured cotton } \\
\hline $\begin{array}{l}\text { Retention } \\
\text { time (min) }\end{array}$ & Compound & $\begin{array}{l}\text { Retention } \\
\text { time (min) }\end{array}$ & Compound \\
\hline 2.606 & 2-Propanone, 1-hydroxy & 16.546 & $1,4: 3,6$-Dianhydro- $\alpha$-d-glucopyranose \\
7.225 & $2(5 H)$-Furanone & 31.029 & $\beta$-D-Glucopyranose, 1,6-anhydro \\
12.860 & Levoglucosenone & 31.759 & 1,6 -Anhydro- $\beta$-D-glucofuranose \\
& 4H-Pyran-4-one, 3,5-dihydroxy-2- & & \\
20.781 & methyl & & \\
21.884 & 1,2,3-Benzenetriol & & \\
23.796 & 5-Hydroxymethylfurfural & & \\
24.443 & 3,4-Dihydro-6-hydroxy-2H-1- & & \\
& benzopyran-2-one & & \\
& (levoglucopyranose, 1,6-anhydro & & \\
\hline
\end{tabular}

Table 3. Selected compounds identified from the Py-GC/MS analysis for raw and scoured cotton fabrics 309 at $530{ }^{\circ} \mathrm{C}$.

\begin{tabular}{|c|c|c|c|}
\hline \multicolumn{2}{|r|}{ Raw cotton } & \multicolumn{2}{|r|}{ Scoured cotton } \\
\hline $\begin{array}{l}\text { Retention } \\
\text { time (min) }\end{array}$ & Compound & $\begin{array}{l}\text { Retention } \\
\text { time (min) }\end{array}$ & Compound \\
\hline 1.693 & Propan-2-one & 4.166 & Methyl 2-oxopropanoate \\
\hline 2.451 & 2-Propanone, 1-hydroxy & 4.586 & Furfural \\
\hline 4.091 & Butanedial & 7.150 & $2(5 H)$-Furanone \\
\hline 4.195 & Methyl 2-oxopropanoate & 7.474 & 1,2-Cyclopentanedione \\
\hline 5.003 & Furfural & 8.380 & 2-Furancarboxaldehyde, 5-methyl \\
\hline 5.074 & 2-Cyclopenten-1-one & 10.421 & $\begin{array}{l}\text { 2-Cyclopenten-1-one, 2-hydroxy-3- } \\
\text { methyl }\end{array}$ \\
\hline 6.940 & Ethanone, 1-(2-furanyl) & 13.197 & 2H-Pyran-2-one \\
\hline 7.115 & Butyrolactone & 13.861 & But-1-ene-3-yne, 1-ethoxy \\
\hline 7.246 & $2(5 H)$-Furanone & 14.048 & $\begin{array}{l}\text { 4H-Pyran-4-one, 2,3-dihydro-3,5- } \\
\text { dihydroxy-6-methyl }\end{array}$ \\
\hline 7.598 & 2-Cyclopenten-1-one, 2-hydroxy & 16.095 & 1,4:3,6-Dianhydro- $\alpha$-d-glucopyranose \\
\hline 8.537 & 2-Cyclopenten-1-one, 3-methyl & 16.903 & 5-Hydroxymethylfurfural \\
\hline 9.088 & Phenol & 30.198 & $\beta$-D-Glucopyranose, 1,6-anhydro \\
\hline 10.572 & $\begin{array}{l}\text { 2-Cyclopenten-1-one, 2-hydroxy-3- } \\
\text { methyl }\end{array}$ & 36.803 & Octadecanoic acid \\
\hline 12.045 & Furyl hydroxymethyl ketone & & \\
\hline 13.168 & $\begin{array}{l}\text { 2-Cyclopenten-1-one, 3-ethyl-2- } \\
\text { hydroxy }\end{array}$ & & \\
\hline 15.799 & 1,2-Benzenediol & & \\
\hline
\end{tabular}


$16.058 \quad 1,4: 3,6$-Dianhydro- $\alpha$-d-glucopyranose

$25.184 \quad \beta$-D-Glucopyranose, 1,6-anhydro

$33.134 \quad n$-Hexadecanoic acid

$36.790 \quad$ Octadecanoic acid

\section{Discussion}

A previous study [8] reported that the improved thermal resistance of mechanically cleaned raw 314 cotton was linked with naturally occurring inorganic salts. Other noncellulosic organic components, such 315 as wax $(0.6 \%)$ and pectin $(0.9 \%)$, present on the outer surface of the fiber [9] were assumed to have 316 relatively small effects on the thermal decomposition of cellulose. In continuation of the work to elucidate 317 the effects of inorganics on the thermal decomposition behavior of cellulose, isothermal treatments and 318 analyses of solid and gaseous products yielded during the pyrolysis were conducted. The early 319 development of carbonyl groups and carbon-carbon double bonds on the solid products and the increased 320 release of pyrolytic water, carbon dioxide, and carbon monoxide observed by FTIR-ATR and TG-FTIR, 321 respectively, indicate that the inorganics accelerated the dehydration of cellulose and the aromatization of 322 char at lower temperatures. Such dehydration is one of the three main chemical pathways proposed by 323 Kilzer and Broido [26]. Traveling this route, occurring at $200-280^{\circ} \mathrm{C}$, cellulose reacts in an endothermic 324 process with the loss of water to yield a "dehydrocellulose." Consistent with the chemical changes 325 observed, the temperature, where the structural organization of cellulose (crystallinity) deteriorated, was 326 lowered for raw cotton. The catalyzed dehydration reaction in raw cotton was further supported by the 327 activation energies determined under isothermal conditions at $200-300{ }^{\circ} \mathrm{C}-124$ and $202 \mathrm{~kJ} / \mathrm{mol}$ for raw 328 and scoured cottons, respectively. As the temperature increases, the other two pathways are involved, i.e., 329 depolymerization of the unreacted cellulose via an endothermic process to produce volatile levoglucosan 330 and decomposition of the "dehydrocellulose" via exothermic reactions to produce light gases and char 331 [26]. Py-GC/MS showed considerable depletion of levoglucosan in raw cotton at 320-530 ${ }^{\circ} \mathrm{C}$. The 332 depolymerization of the residual cellulose was suppressed, because a larger amount of cellulose in raw 
cotton had undergone the dehydration. The combination of the kinetics and analytical studies demonstrate that inorganic salts present in raw cotton allowed dehydration reactions to proceed to the fullest possible extent to prevent a maximum yield of levoglucosan, which is a major constituent of flammable tar, as

336 well as the early formation of aromatic char, which enhanced the yield of carbonaceous char.

\section{Acknowledgements}

We thank Dr. Tina Thomas at the Complex Carbohydrate Research Center for Py-GC-MS measurements. USDA is an equal opportunity provider and employer.

\section{References}

343 [1] Chen HL, Burns LD. Environmental analysis of textile products. Cloth \& Textiles Res J 2006; 24:248-261.

[2] Baydar G, Ciliz N, Mammadov A. Life cycle assessment of cotton textile products in Turkey. Resour Conserv Recy 2015; 104:213-223.

[4] Gary L, Osteen K, Johnson R, Johnson S. True cotton nonwoven fibres. 2014; (http://www.cottoninc.com/product/nonwovens/nonwoven-

353 [5] Hinchliffe DJ, De Lucca A, Condon B, O'Regan J, Clemmons J, Zeng L, et al. A pilot-scale

[6] Singh V, Jinka S, Hake K, Parameswaran S, Kendall RJ, Ramkumar S. Novel natural sorbent for oil spill cleanup. Ind Eng Chem Res 2014; 53:11954-11961.

[7] Sawhney APS, Allen C, Reynolds M, Condon B, Slopek R. Effect of water pressure on absorbency of hydroentangled greige cotton non-woven fabrics. Text Res J 2012; 82:21-26. 
[8] Nam S, Condon BD, Foston MB, Chang S. Enhanced thermal and combustion resistance of cotton linked to natural inorganic salt components. Cellulose 2014; 21:791-802.

[9] Wakelyn PJ, Bertoniere NR, French AD, Thibodeaux DP, Triplett BA, Rousselle M, et al., Cotton Fiber Chemistry and Technology. 2006, Boca Raton: CRC Press.

[10] McCall ER, Jurgens JF. Chemical composition of cotton. Text Res J 1951; 21:19-21.

[11] Broido A, Nelson MA. Char yield on pyrolysis of cellulose Combust Flame 1975; 24:263-268.

[12] Koullas DP, Lois E, Koukios EG. Effect of physical pretreatment on the prepyrolytic behavior of lignocellulosics. Biomass Bioenerg, 1991; 1:199-206.

[13] Maschio G, Koufopanos C, Lucchesi A. Pyrolysis, a promising route for biomass utilization. Bioresour Technol 1992; 42:219-231.

[14] Arseneau DF. Competitive reaction in the thermal decomposition of cellulose. Can J Chem 1971; 49:632-638.

[15] Tsuboi M. Infrared spectrum and crystal structure of cellulose. J Polym Sci 1957; 25:159-171.

[16] Marchessault RH, Liang CY. Infrared spectra of crystalline polysaccharides. III. Mercerized cellulose. J Polym Sci 1960; 43:71-84.

[17] Nelson ML, O'Connor RT. Relation certain infrared bands to cellulose crystallinity and crystal latticed type. Part 1. Spectra of lattice types I, II, III and of amorphous cellulose. J Appl Poly Sci 1964; 8:1311-1324.

[18] Chung C, Lee M, Choe EK. Characterization of cotton fabric scouring by FT-IR ATR spectroscopy. Carbohydr Res 2004; 58:417-420.

[19] Price D, Horrocks AR, Akalin M, Faroq AA. Influence of flame retardants on the mechanism of pyrolysis of cotton (cellulose) fabrics in air. J Analy Appl Pyro 1997; 40-41:511-524.

[20] Skripchenko T, Domburg G, Luksa R. Polyconjugated systems formed during thermal treatment of cellulose. Thermochim Acta 1985; 93:417-420.

[21] Liu Y, Thibodeaux D, Gamble G. Development of Fourier transform infrared spectroscopy in direct, non-destructive, and rapid determination of cotton fiber maturity. Text Res J 2011; 
[22] Liu Y, Thibodeaux D, Gamble G, Bauer P, VanDerveer D. Comparative investigation of Fourier transform infrared (FT-IR) spectroscopy and X-ray diffraction (XRD) in the determination of cotton fiber crystallinity. Appl Spectrosc 2012; 66:983-986.

[23] Basch A, Lewin M. The influence of fine structure on the pyrolysis of cellulose. I. Vacuum pyrolysis. J Polym Sci A Polym Chem 1973; 11:3071-3093.

[24] Weinstein M, Broido A. Pyrolysis-crystallinity relationships in cellulose. Combust Sci Technol 1970; 1:287-292.

[25] Dobele G, Rossinskaja G, Telysheva G, Meier D, Faix O. Cellulose dehydration and depolymerization reactions during pyrolysis in the presence of phosphoric acid. J Analy Appl Pyro 1999; 49:307-317.

[26] Kilzer FJ, Broido A. Speculation on the nature of cellulose pyrolysis. Pyrodynamics 1965; 2:151163.

[27] Liu Q, Wang S, Zheng Y, Luo Z, Cen K. Mechanism study of wood lignin pyrolysis by using TG-FTIR analysis. J Anal Appl Pyrolysis 2008; 82:170-177.

[28] Nevell TP, Zeronian SH, Cellulose Chemistry and its Applications. 1985, New York: Halsted Press, John Wiley.

[29] Schwenker Jr. RF, Beck Jr. LR. Study of the pyrolytic decomposition of cellulose by gas chromatography. J Polym Sci, Part C: Polym Symp 1963; 2:331-340.

[30] Shafizadeh F. Introduction to pyrolysis of biomass. J Analy Appl Pyrolysis 1982; 3:283-305.

[31] Deh S, Gähr F, Buchmeiser M. Synergistic effects in the pyrolysis of phosphorus-based flameretardants: The role of Si- and N-based compounds. Polym Degrad Stab 2016; 130:155-164.

[32] Shen DK, Gu S. The mechanism for thermal decomposition of cellulose and its main products. Bioresour Technol 2009; 100:6496-6504. 